\title{
Attitude and practice of brachytherapy in India: a study based on the survey amongst attendees of Annual Meeting of Indian Brachytherapy Society
}

\author{
Ajeet Kumar Gandhi, MD, Prof. Daya Nand Sharma, MD, Prof. Pramod Kumar Julka, MD, Prof. Goura Kishor Rath, MD \\ Department of Radiation Oncology, All India Institute of Medical Sciences, Ansari Nagar, New Delhi, India
}

\begin{abstract}
Purpose: We performed a survey amongst attendees of the $4^{\text {th }}$ Annual Meeting of Indian Brachytherapy Society to study the patterns of brachytherapy practice and attitude towards brachytherapy use.

Material and methods: A 19-point questionnaire was designed and e-mailed to the attendees immediately after the conference. Descriptive analysis of the responses were done and satisfaction index was used as a tool for evaluation of the program effectiveness. Binomial test was used to assess the difference between distributions of responses and Mann-Whitney $U$ test was used to assess the correlation between responses. $P$ value (2-tailed) of $<0.05$ was taken significant for all statistical analysis.

Results: Of a total of 202 attendees, 90 responded to the survey (response rate: $44.5 \%$ ). Seventy-two percent belonged to an academic institute while $28 \%$ belonged to non-academic institutes. Eighty-six percent were radiation oncologists and $10 \%$ were medical physicists. Eighty-nine percent respondents used high-dose-rate, $14 \%$ - pulse-dose-rate, and $13 \%$ used low-dose-rate brachytherapy facility. Orthogonal X-rays, computed tomography, and magnetic resonance imaging was used for brachytherapy planning by $56 \%, 69 \%$, and $14 \%$, respectively. Ninety-three percent of them thought that lack of training is a hurdle in practicing brachytherapy and $92 \%$ opined that brachytherapy dedicated meetings can change their perception about brachytherapy. Seventy percent respondents admitted to make some changes in their practice patterns after attending this meeting. Ninety-seven percent of them would like to attend future meetings and $98 \%$ felt the need to include live workshops, hands on demonstrations, and video presentations in the scientific programme.

Conclusions: The survey highlights a positive attitude towards increasing brachytherapy use, and may serve as an important guiding tool in designing teaching and training programmes; thus overcoming the hurdles in successful and widespread use of a quality brachytherapy programme at radiotherapy centers.
\end{abstract}

J Contemp Brachytherapy 2015; 7, 6: 462-468 DOI: $10.5114 /$ jcb.2015.55666

Key words: brachytherapy, conference, India, survey.

\section{Purpose}

Brachytherapy has been a time tested and indispensable modality of treatment for a variety of cancers for more than a century. Time and again it has been proven that brachytherapy independently improves survival $[1,2]$ and exclusion of brachytherapy from the management of some cancers can be detrimental $[2,3]$. The data on decline of brachytherapy use [2] needs to be interpreted with caution as sometimes the data from registry or population database could be misleading due to changes in coding and reporting patterns [3]. Apart from established indications $[4,5]$, brachytherapy has expanded wings to novel and innovative indications like brain, liver, penile, lung, and intra-thoracic brachytherapy $[6,7,8,9]$. Brachytherapy planning has also evolved from point based prescrip- tion to volume based and from X-ray based to magnetic resonance imaging (MRI) based planning $[10,11]$.

With the evolution in brachytherapy practice, it is important to know the current change in practice as well as attitude of practicing medical physicians as well as other professionals actively involved in the field. While such surveys are available from the western world [11, 12, 13], one is lacking from India. Available survey [11] also does not address the specific question appropriately and have missing information on the use of interstitial brachytherapy [14]. The burden of cancer in India is different from other parts of the world; having higher incidence of oral cavity cancers and cancers of uterine cervix [15]. The increasing trend towards early detection of cancers [16] may further necessitate increased use of brachytherapy in 
quest of shorter duration of treatment and organ preservation. The limited availability of brachytherapy facilities [17] as well as advanced planning system poses different challenges and hurdles in brachytherapy training and practice in India. Hence, the needs, perspectives, and practices are quite different from the western world.

Attendees of AIIMS-IBS ( $4^{\text {th }}$ Annual Meeting of Indian Brachytherapy Society) meeting are particularly those who are interested and actively involved in the brachytherapy practice, and their opinion may reflect the prevailing scenario of brachytherapy practice. We intended to study the patterns and attitudes of brachytherapy practice though this post-conference descriptive online cross-sectional survey.

\section{Material and methods}

The AIIMS-IBS was held at New Delhi, India from $14^{\text {th }}-16^{\text {th }}$ March, 2014. The scientific program was designed with the objectives of acquainting the post-graduate students and practicing physicians with: 1) indications and techniques of brachytherapy for various malignancy sites; 2) generate awareness about innovations and advances in brachytherapy; 3) expose the attendees to experience of interstitial brachytherapy for difficult sites; 4) motivate the students and physicians for further refining their practice of brachytherapy. The conference included dedicated sessions on brachytherapy in urologic, gastro-intestinal, breast, gynecologic, thoracic, head and neck, soft tissue sarcomas, and cutaneous malignancies. Lectures were delivered by renowned experts on interstitial brachytherapy for less common sites like brain, lung, liver, and bone. Innovative topics among others included organ sparing spacer techniques and integration of systemic therapy with brachytherapy. Other sessions included panel discussion, debates, oral and poster presentations, and video sessions highlighting brachytherapy procedures, plenary talks and interactive sessions of attendees with professors. This descriptive cross sectional study was carried out immediately after the conference. A web based 19-point questionnaire (Table 1) was designed and e-mailed to the attendees. The e-mail contained a brief purpose of the survey and the survey included in the mail itself, and also a web link to access the questionnaire. E-mail and name were used to avoid duplicate submissions. The questionnaire consisted of demographic details (items 1-3), current brachytherapy practice (items 4-5), perception towards education, and change of brachytherapy practice (items 6-11); satisfaction level for present meeting (item 12-13), attitude towards attending and suggestions for improvement of brachytherapy meetings (item 14-19). Items 1-16 were single or multiple choice questions and items 17-19 were descriptive answer type questions. The replies of the respondents were not accessible to other respondents. There was no option of changing the replies once submitted in the web portal. The survey web form was closed on $30^{\text {th }}$ April 2014. Respondents were given the option of concealing their identity and their identity was kept confidential. Descriptive analysis of the responses was done. Binomial test was used to assess the difference between distributions of dichotomous responses. Mann-Whitney $U$ test was used to assess the correlation of Likert-scale responses (item numbers 12-13). Statistical analysis was done with SPSS version 21.0 (SPSS Inc., Chicago, IL, USA). $P$ value (2-tailed) of $<0.05$ was taken significant for all statistical analysis. We used satisfaction index (SI) as suggested by Guilbert et al. [18]:

$$
\mathrm{SI}=[\{(\mathrm{a} \times 1)+(\mathrm{b} \times 2)+(\mathrm{c} \times 4)+(\mathrm{d} \times 5)\} \times 20] / \mathrm{N}
$$

where, $a$ - $d$ are total responses for the co-efficient 1, 2, 4, 5, respectively, and $N$ - total number of participants. Satisfaction index was used for items 12-13 and the co-efficient $1,2,4,5$, respectively, correspond to "Strongly disagree", "Disagree", "Agree", and "Strongly agree". Maximum score possible for SI was 100.

\section{Results}

Of a total of 202 attendees, 90 responded to the survey yielding a response rate of $44.5 \%$. The demographic profiles presented are for the 90 responding attendees. Male : Female ratio for the respondents was $64: 26$. Seventy-two percent of the respondents belonged to an academic institute (institute having radiation oncology teaching programme) while $28 \%$ belonged to non-academic/ private institutes. Eighty-six percent were radiation oncologists and $10 \%$ were medical physicists. $28.9 \%$ were post-graduate students, $13.3 \%$ were post graduate registrars, and rests of them were faculties.

Eighty-nine percent respondents used high-dose-rate, $14 \%$ - pulsed-dose-rate, and $13 \%$ - low-dose-rate brachytherapy facility. Orthogonal X-rays, computed tomography $(\mathrm{CT})$, and MRI was used for brachytherapy planning by $56 \%, 69 \%$, and $14 \%$, respectively. Table 2 summarizes the descriptive response of the participants to items 6-11. Thirty-six percent of the respondents strongly agreed to fact that the scientific content of the meeting pertained to the needs of the brachytherapy education; while $56 \%$ agreed and $8 \%$ disagreed to this (Mann-Whitney; $p=0.006$ ). Seventeen percent strongly agreed and $50 \%$ agreed to the notion that the scientific programme of the present meeting was comparable to the international conferences. At the same time, 33\% disagreed to this notion (Mann-Whitney; $p=0.023$ ). Satisfaction index to scientific content of the present meeting was $80 \%$ and SI as compared to international brachytherapy meeting was $75 \%$. Ninety-six percent felt that initiative should be taken to start national and international fellowships for promotion of training in brachytherapy. Ninety-seven percent desired to attend future national/international workshops/ conferences on brachytherapy and $98 \%$ felt the need to include live workshops, hands on demonstrations, and video presentations in the scientific programme.

The most liked presentation/session was debate (Can intensity modulated radiotherapy replace interstitial brachytherapy in carcinoma cervix?) followed (in that order) by video presentation session, lectures on interstitial brachytherapy for brain tumors, and interstitial brachytherapy for pediatric and soft tissue sarcomas. Respondents were inclined towards changing their 
Table 1. Web Survey Form

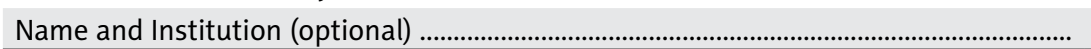

1. Type of Institution

Answer Choices

Government medical college

Private Institution with teaching facility

Private institution

Others

2. Are you a .....?

Radiation oncologist

Medical Physicist

Others

3. Present affiliation

Teaching faculty

Faculty

Resident

Medical Physicist

Others

4. What brachytherapy facility do you have at your center? (check all that apply)

High-dose-rate

Low-dose-rate

Pulse-dose-rate

Manual after loading

Others

5. What imaging modality do you use for brachytherapy planning at your centre?

(check all that apply)

Orthogonal X-ray

CT

MRI

Others

$\begin{array}{ll}\text { 6. Do you think lack of training/education is a hurdle in practicing brachytherapy? Yes } & \text { No }\end{array}$

Don't know

7. Do you think conferences like AlIMS-IBS can make a change in the way you perceive Yes brachytherapy?

No

Don't know

8. Based on the lectures in the conference, would you prefer brachytherapy to other Yes conformal radiotherapy wherever applicable like brachytherapy for liver malignancies No instead of intensity modulated radiotherapy or stereotactic body radiotherapy?

Don't know

9. Would you change your practice patterns (indications of brachytherapy, techniques Yes etc.) after attending AlIMS-IBS?

No

Don't know

10. Would you discuss innovative techniques of brachytherapy viz. brachytherapy for Yes brain tumors, liver and lung malignancies, penile tumors, and spacer techniques pre- No sented in the conference with your colleagues?

11. Do you feel that medical council of India should make it mandatory for radiotherapy Yes centers to have brachytherapy facility?

Don't know

Yes

No

Don't know

12. Scientific content of AIIMS-IBS pertained to the needs of brachytherapy education Strongly disagree

and it was good?

Disagree

Agree

Strongly agree

13. Scientific programme of AIIMS-IBS was comparable to international brachytherapy Strongly disagree conferences viz. ABS.

Disagree

Agree

Strongly agree

14. Would you like to attend future national/international conferences on brachyther- Yes apy?

No

Don't know

15. Do you feel Indian brachytherapy society should take the initiative to start national/ Yes international fellowships for training in brachytherapy?

No

Don't know

16. Do you think brachytherapy meetings should include live workshops/demonstra- Yes

tions/video presentations in the scientific program? No

Don't know

17. What one change would you bring or think to bring to your practice of brachytherapy after attending the AlIMS-IBS? .

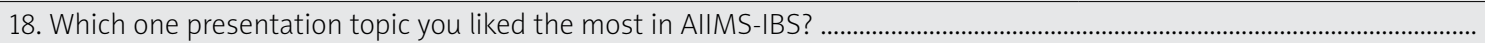

19. How can future annual meetings of Indian Brachytherapy Society be further improved? (please suggest if any)

CT - computed tomography, MRI - magnetic resonance imaging, AlIMS-IBS - $4^{\text {th }}$ Annual meeting of Indian Brachytherapy Society 
Table 2. Descriptive analysis of participant's response $(N=90)$ [items 6-11]

\begin{tabular}{|c|c|c|c|}
\hline Parameter & Yes & No & $\begin{array}{l}\text { Binomial test } \\
\quad(p \text { value })\end{array}$ \\
\hline Do you think lack of training/education is a hurdle in practicing brachytherapy? & $84(93 \%)$ & $4(7 \%)$ & 0.0001 \\
\hline $\begin{array}{l}\text { Do you think conferences like the present one can make a change in the way you } \\
\text { perceive brachytherapy? }\end{array}$ & 83 (92\%) & $6(8 \%)$ & 0.0001 \\
\hline $\begin{array}{l}\text { Based on the lectures in the conference, would you prefer brachytherapy to other } \\
\text { conformal radiotherapy wherever applicable like brachytherapy for liver malig- } \\
\text { nancies instead of intensity modulated radiotherapy or stereotactic body radio- } \\
\text { therapy? }\end{array}$ & 64 (71\%) & $21(29 \%)$ & 0.0001 \\
\hline $\begin{array}{l}\text { Would you change your practice patterns (indications of brachytherapy, tech- } \\
\text { niques etc.) after attending the present conference? }\end{array}$ & $63(70 \%)$ & $19(30 \%)$ & 0.0002 \\
\hline $\begin{array}{l}\text { Would you discuss innovative techniques of brachytherapy viz. brachytherapy for } \\
\text { brain tumors, liver and lung malignancies, penile tumors, and spacer techniques } \\
\text { presented in the conference with your colleagues? }\end{array}$ & 83 (92\%) & $5(8 \%)$ & 0.0001 \\
\hline $\begin{array}{l}\text { Do you feel that medical council of India should make it mandatory for radiother- } \\
\text { apy centers to have brachytherapy facility? }\end{array}$ & 76 (84\%) & $6(16 \%)$ & 0.0001 \\
\hline
\end{tabular}

brachytherapy practices like use of ablative brachytherapy for liver, lung, and penile malignancies. Participants also felt the need to start multi-institutional collaboration for trials on brachytherapy, initiate brachytherapy tumor boards in concert with surgical oncologists, and also involve residents by focusing on brachytherapy based thesis and $\mathrm{PhD}$ projects. The respondents also felt the needs of the following for better educational experience from the brachytherapy dedicated conferences/workshops:

- Hands on training and demonstration for limited groups

- Live pre-conference brachytherapy procedure workshops

- Video presentations on common as well as difficult brachytherapy procedures

- Quiz for the post-graduate residents

- Debate topics and panel discussions

- Organ specific/site wise workshops and symposiums

- Contouring sessions for image based brachytherapy

- Radiobiology and physics topics pertaining to clinical and basic brachytherapy principles

- Interactive/brain storming sessions with post-graduate students

\section{Discussion}

Teaching and training programmes are integral part of physician's learning and helps in updating knowledge of the subject. Scientific meetings having well designed programmes can bridge gaps in understanding of the subject and also update the knowledge regarding various aspects viz. clinical, biological, and technological advancements. It can further promote learning by motivating the physicians and also by encouraging self-directed learning in the long run. Donald Kirkpatrick [19] published four level training evaluation models in 1959 and subsequently updated their work in 1994. The accepted levels of evaluation are: reaction, learning, behavior, and results. Of these, reaction and learning can be evaluated by survey questionnaire. Although, learning is best assessed by pre-post inter- vention test, this can also be reliably done with a retrospective questionnaire as has been used by us in this study. We intended to analyze the reaction as well learning, attitudes and practices of brachytherapy, and gain feedback from attendees in order to further improve future brachytherapy meetings.

The majority of attendees belonged to academic institutes $(70 \%), 30 \%$ of respondents were residents and this reflects the inquisitiveness of younger generation towards learning nuances of brachytherapy. Most of them are using high dose rate brachytherapy facilities (89\%). Fifty-three percent use orthogonal X-ray based treatment planning and this is corroborative with $43 \%$ members in United States [11]. Computed tomography and MRI based brachytherapy planning in our study as compared to study by Viswanathan et al. [11] was $69 \%$ vs. $55 \%$, and $14 \%$ vs. $2 \%$, respectively. The discrepancy could be because of the different time points of survey and also overrepresentation of academic/teaching institutes in our study.

Brachytherapy is in true sense a multidisciplinary field and its practice has a learning curve. Acquisition of skills, advancement of knowledge over time as well as clinical experience acquired with more number of cases can affect the ultimate outcome of the patients, and this has been proven by Le Fur et al. [20] and Liu et al. [21] in their studies on brachytherapy implants for prostate cancers. Hence, it is important to infuse the interest of brachytherapy in the beginning of the radiation oncology teaching programme. While brachytherapy has been placed as a mandatory subject in the curriculum of postgraduate teaching/training program of radiation oncology in India [22], a structured brachytherapy curriculum with defined goal is lacking. A written and designed program directive was available to only $54 \%$ of the training residents in the study by Gaudet et al. [13]. In the same study, main barriers to brachytherapy education were lack of written guidance $(55 \%)$, clinical workload $(49 \%)$, and lack of time $(37 \%)$. The barriers to practicing brachytherapy are mainly lack of infrastructure and inad- 
equate training rather than insufficient patient numbers or absence of scientific evidence favoring brachytherapy [23]. Acquisition of skill in brachytherapy is a time taking process and it is disturbing to note physicians discontinuing practice of brachytherapy owing to reassignment and lack of a local program, and this could be as high as $49 \%$, as noted in the Canadian survey by Rose et al. [23]. The authors also noted that the common sites discontinued were head and neck cancers, cervical cancers, and endometrial cancers, and ironically scientific evidence for the use of brachytherapy in these sites are time-proven and robust. In another study by Fumagalli et al. [24], 82\% of the residents felt that insufficient teaching has been imparted to them during residency and only $50 \%$ performed one brachytherapy treatment during residency. The interest of brachytherapy among residents in training is guided mainly by requirement of the accreditation council [25] as well as the benefit of knowledge of brachytherapy in staff recruitment [23]. Compton et al. [25] found a decreasing trend in the mean number of brachytherapy procedures performed by residents (80.8 in 2006-2007 to 71.0 in 2010-2011) and also a decrease in the average number of interstitial procedures by $25 \%$. The trend in decline of brachytherapy training experience should be an alert to the community of brachytherapy and avenues must be created to increase the interest as well as provide more opportunities for training. Gaudet et al. [13] suggested introduction of a formal credentialing and certification process in brachytherapy, and this was supported by $80 \%$ and $81 \%$ of practicing radiation oncologists and residents, respectively. Although, a final solution of this issue may lie in bringing changes in the residency programs to better suit the needs of brachytherapy teaching, educational activities like conferences may be the initial motivating step. Ninety-two percent in our survey felt that this conference has changed the way they perceive brachytherapy and $70 \%$ were likely to change their practice patterns after this meeting. Eighty-four percent felt that regulatory authorities should approve comprehensive radiotherapy centres only if they have brachytherapy facilities, and this might improve the availability and indirectly the scope of skill development.

Brachytherapy has emerged as a competitive option to external beam therapy/surgery in many clinical situations [26, 27, 28, 29]. While modern external beam radiotherapy techniques can give an aesthetically appealing dose distribution, it cannot match the dose conformity achieved with brachytherapy. Ninety-two percent of the attendees committed to prefer brachytherapy to intensity modulated radiotherapy or stereotactic ablative radiotherapy in clinically relevant situations. Novel and innovative indications of brachytherapy has also brought a state of dilemma in some of the physician's mind, particularly those not adequately trained in brachytherapy. Debates on cutting and controversial issues may be the best form to discuss and prove the most suited form of radiation modality, and it also leaves more impact on young mind of the residents. This is also supported by the results of our study; most liked presentation in our study was debate comparing role of brachytherapy ver- sus modern external beam radiotherapy techniques in the management of cervical cancer. This form of discussion should be encouraged at future brachytherapy meetings.

With the technical advancement, the modes of teaching have also become more sophisticated. Novel methods of imparting training and skills have been developed. Use of phantom simulator for prostate and gynecological brachytherapy has been described by Thaker et al. [30] and de Almeida et al. [31], respectively. Such facilities, although desirable, may not be available at most centres. Other modes of teaching like video presentation, hands on training, and live demonstration might be very useful to attendees of the brachytherapy meeting. Ninety-eight percent of the respondents in our survey also felt the need to include the same in brachytherapy meetings. The internationally accepted norm for the unsatisfactory outcome for SI is at $<60 \%$ [18]. Satisfaction index for the scientific content of the present meeting as well as it's comparison with international meetings were $80 \%$ and $75 \%$, respectively. Although use of SI index for brachytherapy meetings is lacking, Singh et al. [32] used SI index to evaluate their continued medical education program and found their program to have an index of $85-87 \%$ for various satisfaction endpoints. The current SI index of our study reflects the effectiveness of the present scientific deliberations as well as scope for future improvement in the planning, conduct and content of the national brachytherapy meetings.

Overall, the meeting shows an impressive impact on the attendees in terms of gaining new knowledge, change in perception and attitudes towards brachytherapy as well as in terms of motivation for further educational activities. Ninety-seven percent of the attendees wished to attend future meetings on brachytherapy. Our study highlights the needs and demands of the practicing physicians and residents pertaining to brachytherapy. The views of the attendees reflect the need for courses directed towards practical skill development of brachytherapy. Our study provides the program objectives to be kept in mind in the design and conduct of brachytherapy educational activity. Hands on training and practical demonstration of brachytherapy procedures would stimulate interest as well as help in development of skill and confidence.

Our study has several limitations. The opinion of the attendees of the meeting might not be a true representation of the entire radiotherapy community interested in brachytherapy. A smaller sample size of the respondents is another shortcoming in itself. Although a more approprate way of doing a survey is to include individuals from each single institution practicing brachytherapy, the hurdles of doing the above in reality are tremendous. There is no national database of the practicing radiation oncologists and membership to societies is also not universal. Functioning brachytherapy facilities are limited in number and all institutions might not be accessible to these surveys. Surveys of a specific community (like attendees of brachytherapy/workshop meeting) might be a quick and informative way to capture scenario and patterns of practice. Similar to ours, Buyyounouski et al. [33] surveyed 
the attendees of $7^{\text {th }}$ American Brachytherapy Society prostate brachytherapy school and accepted the bias inherent to such surveys. A further follow up survey from these respondents would be able to assess the change in behavior and long term impact on the practice patterns arising out of this educational activity. Nevertheless, this remains the only survey from India pertaining to brachytherapy attitudes and practices. The practice patterns reported in our study may be very useful for comparison with the internationally reported literature and may also provide insights in formulation and conduct future nationwide surveys.

Challenges and hurdles faced by us in brachytherapy teaching, training and education may not be unique to our country and in fact would be shared by many of the other countries where brachytherapy practice is sparse, diverse, and not standardized like ours. This is reflected by the absence of such surveys from other parts of the world except USA and Canada. The results of our study would encourage other countries to take up these surveys and understand the knowledge, attitudes, and practices specific to them as well as common to ours. This may further yield solutions and ideas, which could be applicable in a wider sense.

\section{Conclusions}

In summary, the survey highlights the attitude, perception, and practices of brachytherapy in India. Majority use high dose rate brachytherapy facility and CT scan is the commonest imaging modality used for brachytherapy planning. Results of our study would provide invaluable inputs in the design of not only brachytherapy teaching programs in institutes but also help in the design and conduct of training and educational programs pertaining to brachytherapy both in and outside India.

\section{Acknowledgment}

We thank all the respondents of this survey for their valued opinion.

\section{Disclosure}

The study was presented in abstract form as poster presentation (PO 53) at the $36^{\text {th }}$ annual meeting of the American Brachytherapy Society at Florida, USA (April 9-11, 2015); Brachytherapy 2015: 14 (Supplement 1); S-102-103.

Authors report no conflict of interest.

\section{References}

1. Acharya S, Perkins SM, DeWees T et al. Brachytherapy is associated with improved survival in inoperable stage I endometrial adenocarcinoma: A population-based analysis. Int J Radiat Oncol Biol Phys 2015; 93: 649-657.

2. Han K, Milosevic M, Fyles A et al. Trends in the utilization of brachytherapy in cervical cancer in the United States. Int J Radiat Oncol Biol Phys 2013; 87: 111-119.

3. Smith GL, Eifel PJ. Trends in the utilization of brachytherapy in cervical cancer in the United States. In regard to Han et al. Int J Radiat Oncol Biol Phys 2014; 88: 459-460.

4. Skowronek J. Brachytherapy in the therapy of prostate cancer - an interesting choice. Contemp Oncol (Pozn) 2013; 17: 407-412.
5. Skowronek J, Chicheł A. Brachytherapy in breast cancer: an effective alternative. Prz Menopauzalny 2014; 13: 48-55.

6. Tanderup K, Eifel PJ, Yashar CM et al. Curative radiation therapy for locally advanced cervical cancer: brachytherapy is NOT optional. Int J Radiat Oncol Biol Phys 2014; 88: 537-539.

7. Archavlis E, Tselis N, Birn G et al. Combined salvage therapies for recurrent glioblastoma multiforme: evaluation of an interdisciplinary treatment algorithm. J Neurooncol 2014; 119: 387-395.

8. Sharma DN, Thulkar S, Sharma S et al. High-dose-rate interstitial brachytherapy for liver metastases: first study from India. J Contemp Brachytherapy 2013; 5: 70-75.

9. Sharma DN, Joshi NP, Gandhi AK et al. High-dose-rate interstitial brachytherapy for T1-T2-stage penile carcinoma: shortterm results. Brachytherapy 2014; 13: 481-487.

10. Tselis N, Ferentinos K, Kolotas C et al. Computed tomography-guided interstitial high-dose-rate brachytherapy in the local treatment of primary and secondary intrathoracic malignancies. J Thorac Oncol 2011; 6: 545-552.

11. Viswanathan AN, Erickson BA. Three-dimensional imaging in gynecologic brachytherapy: a survey of the American Brachytherapy Society. Int J Radiat Oncol Biol Phys 2010; 76: 104-109.

12. Pavamani S, D'Souza DP, Portelance L et al. Image-guided brachytherapy for cervical cancer: a Canadian Brachytherapy Group survey. Brachytherapy 2011; 10: 345-351.

13. Gaudet M, Jaswal J, Keyes M. Current state of brachytherapy teaching in Canada: a national survey of radiation oncologists, residents, and fellows. Brachytherapy 2015; 14: 197-201.

14. Sharma DN. A critique of "American Brachytherapy Society Survey of three-dimensional imaging in gynecologic brachytherapy". J Cancer Res Ther 2010; 6: 400-401.

15. Mallath MK, Taylor DG, Badwe RA et al. The growing burden of cancer in India: epidemiology and social context. Lancet Oncol 2014; 15: 205-212.

16. Tiwari V, Shukla P, Gupta G. Changing trends of breast cancer awareness in young females of north India: A pilot study from a rural cancer hospital. Int J Med Public Health 2014; 4: 62-65.

17. Banerjee S, Mahantshetty U, Shrivastava S. Brachytherapy in India - a long road ahead. J Contemp Brachytherapy 2014; 6: 331-335.

18. Guilbert JJ. How to organize an Educational Workshop. In: Educational Handbook for Health Personnel. Guibert JJ. $6^{\text {th }}$ ed. World Health Organization, Geneva 1987, pp. 5.01-5.34.

19. Kirkpatrick DL, Kirkpatrick JD. Evaluating training programs: The four levels. $3^{\text {rd }}$ ed. Berrett-Koehler Publishers, San Francisco 2008.

20. Le Fur E, Malhaire JP, Baverez D et al. Impact of learning curve and technical changes on dosimetry in low-dose brachytherapy for prostate cancer. Strahlenther Onkol 2012; 188: 1091-1095.

21. Liu HW, Malkoske K, Sasaki D et al. The dosimetric quality of brachytherapy implants in patients with small prostate volume depends on the experience of the brachytherapy team. Brachytherapy 2010; 9: 202-207.

22. PG syllabus for MD radiotherapy in India; http://www. fmsc. ac.in/curriculum/Curriculum\%20for\%20PG\%20-\%20 Radio\%20Therapy.pdf

23. Rose J, McLaughlin PY, Falkson CB. Brachytherapy practice across Canada: A survey of workforce and barriers. Brachytherapy 2013; 12: 615-621.

24. Fumagalli I, Faivre JC, Thureau $S$ et al. Brachytherapy training: a survey of French radiation oncology residents. Cancer Radiother 2014; 18: 28-34.

25. Compton JJ, Gaspar LE, Shrieve DC et al. Resident-reported brachytherapy experience in ACGME-accredited radiation oncology training programs. Brachytherapy 2013; 12: 622-627. 
26. Sharma DN, Gandhi AK, Sharma $S$ et al. Interstitial brachytherapy vs. intensity-modulated radiation therapy for patients with cervical carcinoma not suitable for intracavitary radiation therapy. Brachytherapy 2013; 12: 311-316.

27. Ryken TC, Hitchon PW, VanGilder JC et al. Interstitial brachytherapy versus cytoreductive surgery in recurrent malignant glioma. Stereotact Funct Neurosurg 1994; 63: 241-245.

28. Park DS, Gong IH, Choi DK et al. Radical prostatectomy versus high dose permanent prostate brachytherapy using iodine-125 seeds for patients with high risk prostate cancer: a matched cohort analysis. World J Urol 2013; 31: 1511-1517.

29. Kuske RR, Young SS. Breast brachytherapy versus wholebreast irradiation: reported differences may be statistically significant but clinically trivial. Int J Radiat Oncol Biol Phys 2014; 88: 266-268.

30. Thaker NG, Kudchadker RJ, Swanson DA et al. Establishing high-quality prostate brachytherapy using a phantom simulator training program. Int J Radiat Oncol Biol Phys 2014; 90: 579-586.

31. de Almeida CE, Rodriguez M, Vianello E et al. An anthropomorphic phantom for quality assurance and training in gynaecological brachytherapy. Radiother Oncol 2002; 63: 75-81.

32. Singh K, Sharma B, Misra S et al. Determination of Satisfaction Index as a tool in evaluation of CME Program. Ann Natl Acad Med Sci (India) 2013; 49: 185-193.

33. Buyyounouski MK, Davis BJ, Prestidge BR et al. A survey of current clinical practice in permanent and temporary prostate brachytherapy: 2010 update. Brachytherapy 2012; 11: 299-305. 